\title{
Predictors and dietary consequences of frequent intake of high-sugar, low-nutrient foods in 1-year-old children participating in the ABIS study
}

\author{
Hilde K. Brekke ${ }^{1}$, Jenny van Odijk ${ }^{1}$ and Johnny Ludvigsson ${ }^{2}$ \\ ${ }^{1}$ Department of Clinical Nutrition, Sahlgrenska Academy at Göteborg University, Box 459, 40530 Göteborg, Sweden \\ ${ }^{2}$ Division of Pediatrics and Diabetes Research Centre, Department of Molecular and Clinical Medicine, Faculty of Health \\ Sciences, Linköping University, Linköping, Sweden
}

(Received 7 December 2005 - Revised 11 September 2006 - Accepted 14 September 2006)

\begin{abstract}
Foods rich in sugar have been suggested to contribute to the increasing prevalence of obesity in children. The aim of this report is to investigate the dietary pattern in 1-year-old children who frequently receive foods rich in sugar but low in nutrients and to study associated demographic and parental factors. During 1977-9, 21700 infants were invited to participate in this prospective, population-based, longitudinal cohort study. Screening questionnaires were completed for 16070 infants after delivery. Follow-up questionnaires from 10762 children at 1 year of age are included in the analysis. It was found that $24 \%$ of the children received sweets/pastries more often than one or two times per week. They had a higher intake of French fries, potato crisps and cream as well as a lower intake of fruit and vegetables. A frequent intake of sugar-rich, low-nutrient foods was significantly associated with several maternal factors (high intake of sweets/pastries during pregnancy, young age, mother living alone) as well as presence of older siblings. Maternal smoking during pregnancy and maternal overweight were of borderline significance. Parental education level was inversely associated with the frequency of intake of sweets/pastries in the child. Children who frequently receive sweets/pastries also have an otherwise unfavourable dietary pattern. Several parental and demographic factors were associated with this feeding pattern, especially high intake of sweets/pastries during pregnancy. Screening of pregnant women for risk predictors like consumption of sweets/pastries, young age and smoking could be possible ways of identifying children at future risk for low dietary quality.
\end{abstract}

High-sugar foods: Low-nutrient foods: Children: Risk predictors: Dietary quality

Refined sugars, as well as dietary fat, have been suggested to contribute to development of obesity in children (Ludwig et al. 2001; Foreyt \& Poston, 2002). Consumption data from Sweden show that total consumption of sugar during the last 30 years has been relatively stable, however, use has shifted from those in desserts and as granulated sugar/cube sugar towards more use in commercially produced foods like soft drinks and sweets (National Food Administration, 2003).

Foods rich in refined sugars contribute 'empty calories' since they often contain few nutrients but have high energy content. Small children have a high energy and nutrient need per $\mathrm{kg}$ body weight and nutrition recommendations therefore aim at limiting intake of refined sugars and foods contributing with 'empty calories' (Nordic Council of Ministers, 2004). Sweet foods, often rich in fat, like chocolate, cakes/cookies and sweets, have traditionally been consumed about once a week (Saturday sweets) in Sweden. However, the frequency of intake may have changed as the production of these foods has increased and they have become more available to consumers.

A frequent intake of foods high in added sugar but low in nutrients may lower the nutritional value of the total diet. In a Norwegian study, a high intake of added sugar showed negative association with intakes of micronutrients, fruit and vegetables in children (Overby et al. 2004). It is also possible that frequent consumption of sugar-rich foods is associated with a certain, less varied eating pattern that additionally decreases total nutrient intake. More use of added sugar and sugar-sweetened beverages as well as a poorer diet quality has been shown in children who regularly eat foods from fast-food places (Bowman et al. 2004).

A number of parental socio-demographic characteristics have been associated with children's dietary patterns (North \& Emmett, 2000; Kranz \& Siega-Riz, 2002; Aranceta et al. 2003; Rogers \& Emmett, 2003; Vereecken et al. 2004; Northstone \& Emmett, 2005). Poorer dietary quality and high added sugar intake has been observed in groups of lower socio-economic status (Kranz \& Siega-Riz, 2002; Shahar et al. 2005). In addition, mothers' attitudes and beliefs as well as preferences have been shown to be predictors of children's dietary intake (Gibson et al. 1998; Vereecken et al. 2004).

Identifying children at risk of poor diet quality, and possibly future obesity, will be important when planning prevention strategies. Such strategies should probably start as early as possible in life. If risk individuals can be identified before the child is born, extra support and nutritional guidance can be given to these parents.

The aim of the present report is to investigate the dietary pattern in 1-year-old children who frequently receive low-nutrient foods 
that are high in added sugar (sweets/pastries), and compare this to the dietary pattern in children who less frequently receive these foods. Second, demographic and parental factors associated with a frequent intake of sweets/pastries as well as early introduction of sweets and sugar-sweetened drinks are studied.

\section{Material and methods}

The present report is based on the 1-year follow-up of infants who are part of the ABIS study (All Babies in Southeast Sweden). Parents to 21700 newborn babies were invited to participate in this prospective cohort study from 1 October 1997 to 1 October 1999. Mothers of 16070 infants completed a screening questionnaire after delivery. That questionnaire was completed just before leaving the maternity ward or at home (and in the latter case returned to the responsible nurse/doctor at the time of regular infant check-up within a week). Follow-up questionnaires from 1 year of age were available from 11081 participants. In order to limit the variation in age at examination, children examined between 9 and 18 months ( $n$ 10762) were included in the analysis. Among the included children there was a slight under-representation of younger parents, low education level in the mother, parents of foreign origin and smoking during pregnancy compared to the 16070 children participating at birth. In addition to the follow-up questionnaires, 9849 detailed food diaries, covering the gradual inclusion of different foods during the first year, were available.

Baseline data about the parents and associated factors were collected from the screening questionnaires at birth. The 1-year follow-up questionnaire contained a food frequency questionnaire regarding twenty-six different foods in addition to questions regarding breastfeeding and time of introduction of certain solid foods. The frequency categories most often used were: (A) daily, (B) three to five times per week, (C) one or two times per week and (D) more seldom. The detailed food diary included additional information about breastfeeding duration and time (date) of introduction of food items (including sweets and sugar-sweetened drinks) during the first year. The food diary was handed out at screening and collected at the 1-year examination. Participants were instructed to register every new food item that was included in the child's diet at the time they were introduced. Data from the detailed food diary were only used to examine the timing for introduction of sweets and sugar-sweetened drinks. All other data were collected from the 1-year follow-up questionnaire.

\section{Definitions}

Frequent maternal intake of sweets/pastries during pregnancy is defined as mother eating chocolate or sweets or cakes/ cookies three to five times per week or more. A frequent intake of sweets/pastries in the 1-year-old child is defined as eating chocolate or sweets or cakes/cookies more often than one or two times per week. Early introduction of sweets and sugar-sweetened drinks was defined as introducing these foods at day 240 of the child's life or earlier.

\section{Statistical analysis}

Data are presented as means and standard deviations. Pearson $\chi^{2}$ was used to compare the frequency distribution of foods in those with a frequent consumption of sweets/pastries and those without. Odds ratios (OR) with $95 \%$ CI were estimated using logistic regression. Time of introduction of sweets and sugarsweetened drinks was compared using a $t$ test. A significance level of $p<0.05$ was considered statistically significant. SPSS for Windows version 11.5.1 (SPSS Inc., Chicago, IL, USA) was used for all statistical analysis.

\section{Ethics}

The present study was part of the ABIS study (All Babies In Southeast Sweden), which has been approved by the Research Ethics Committees of the Faculty of Health Sciences, Linköping University and the Medical Faculty of Lund University. Mothers gave their consent after careful written as well as oral information and information via videotape.

\section{Results}

Characteristics of the parents and the infants are presented in Table 1 and based on 10762 included infants. The average age of the participating infants at the time of the follow-up was $12 \cdot 0$ (SD 1.1) months.

The proportion of children that received either chocolate, sweets or cakes/cookies more often that one or two times per week was $24 \%$. These children had a lower frequency of intake of fruit and berries, vegetables, potatoes and beef (Table 2(A)) compared to the children who received these foods more seldom. They also had a higher frequency of intake of bread, cheese, milk/yoghurt/sour milk, cream, eggs, pork and sausage as well as potato crisps and French fries (Table 2(A, B)).

A frequent intake of sweets/pastries (more than one or two times per week) at the age of 1 year was significantly associated with a frequent maternal intake of sweets/pastries during pregnancy, the child having older siblings, and the mother being $<25$ years when giving birth to the child (Table 3 ). The mother living alone at the time of birth of the child was also positively associated with frequent intake of these foods in the child while maternal smoking during pregnancy and a maternal BMI $>25$ were of borderline significance. Parental education level was inversely associated with the frequency of intake of sweets/pastries in the child.

Data from the food introduction diary showed that mean time for introduction of sweets and sugar-sweetened drinks were on days 277 and 266 from birth, respectively. Frequent eaters of sweets and pastries at 1 year were introduced to sweets and sugar-sweetened beverages on average $25(95 \%$ CI 21, 30; $P<0.001)$ and $24(95 \%$ CI 20, 29, $P<0.001))$ $\mathrm{d}$ earlier than other children, respectively. Parental and demographic factors associated with early introduction of sweets were mother having a $\mathrm{BMI}>25$, mother smoking during pregnancy and frequent intake of sweets/pastries during pregnancy (Table 3). Duration of exclusive breastfeeding was inversely associated with introduction of sweets as well as introduction of sugar-sweetened drinks. Other factors associated with early introduction of sugar-sweetened drinks were maternal BMI $>25$, younger than 25 years of age at the time of the child's birth, smoking during pregnancy and mother living alone at the time of the child's birth. The mother being from Sweden and maternal education level were inversely associated with introduction of sugar-sweetened drinks. 
Table 1. Characteristics of the parents at the time of delivery and the characteristic of the child at birth and at the 1-year follow-up*

(Mean values and standard deviations)

\begin{tabular}{|c|c|c|}
\hline Characteristic & Mean & SD \\
\hline Maternal age at delivery (years) & $29 \cdot 8$ & 4.5 \\
\hline Paternal age at delivery (years) & $32 \cdot 2$ & 5.4 \\
\hline \multicolumn{3}{|l|}{ Education level of mother (\%) } \\
\hline$\leq 9$ years & $7 \cdot 3$ & \\
\hline $10-12$ years & $59 \cdot 4$ & \\
\hline$\geq 13$ years & $33 \cdot 3$ & \\
\hline \multicolumn{3}{|l|}{ Education level of father (\%) } \\
\hline$\leq 9$ years & $13 \cdot 2$ & \\
\hline $10-12$ years & $62 \cdot 2$ & \\
\hline$\geq 13$ years & $24 \cdot 7$ & \\
\hline Maternal smoking during pregnancy (\%) & $9 \cdot 3$ & \\
\hline Swedish mother (\%) & 94.3 & \\
\hline Non-Swedish mother (\%) & $5 \cdot 7$ & \\
\hline Swedish father (\%) & 93.9 & \\
\hline Non-Swedish father (\%) & $6 \cdot 1$ & \\
\hline Primiparous (\%) & $39 \cdot 2$ & \\
\hline \multicolumn{3}{|l|}{ Marital stats at birth of child (\%) } \\
\hline Single mother & 1.6 & \\
\hline Co-habitant & 55.5 & \\
\hline Married & $42 \cdot 9$ & \\
\hline Maternal BMI at 1-year follow-up & $23 \cdot 7$ & 3.9 \\
\hline Paternal BMI at 1-year follow-up & $25 \cdot 0$ & $3 \cdot 0$ \\
\hline$n$ & 10762 & \\
\hline Boys (\%) & 51.9 & \\
\hline Girls (\%) & $48 \cdot 1$ & \\
\hline Age at follow-up (months) & $12 \cdot 0$ & $1 \cdot 1$ \\
\hline Weight at 1 year $(\mathrm{g})$ & 10170 & 3164 \\
\hline Length at 1 year $(\mathrm{cm})$ & $76 \cdot 0$ & $13 \cdot 6$ \\
\hline
\end{tabular}

* Children examined at the age of 9-18 months are included in the analysis.

\section{Discussion}

The present study indicates that children who are frequently fed sweets, chocolate, cookies and cakes also have more frequent intakes of other less healthy foods like potato crisps, French fries and cream compared to children that are less frequently fed sugar-rich, low-nutrient foods. In addition, they have less frequent intakes of foods that are considered healthy like fruit and berries, vegetables and potatoes. A frequent intake of sweets/pastries in the child showed association with maternal intake of sweets/pastries during pregnancy, the child having older siblings but also with maternal age $(<25$ years), marital status and low parental education level. Similar associations were seen between these factors and early introduction of sweets and sugar-sweetened drinks.

Other studies have linked sugar intake to reduced dietary quality in children (Bowman et al. 2004; Overby et al. 2004). In the population of children in the present study, a frequent intake of sweets/pastries was associated with more frequent intakes of typically high-fat foods like potato crisps, French fries and cream. High-fat foods are considered a risk factor for development of obesity, which together with a high sugar consumption might further increase this risk (Foreyt \& Poston, 2002). At the age of 1 year, a high intake of dietary fat has not been associated with increased risk of future obesity (Parsons et al. 1999), on the contrary, a higher fat intake is recommended (Nordic Council of Ministers, 2004). However, a high nutrient quality of the diet is also recommended for these children, limiting space for foods of low nutritional value. Besides, from the age of 2 years, current nutrition recommendations are the same as for the general population. Dietary habits and taste preferences are founded early (Pepino \& Mennella, 2005). Therefore, healthy food choices at an early stage in life can be of great importance for children's future development and well-being.

There was a strong association between the mother's intake of sweet foods during pregnancy and the child's intake of these foods at the age of 1 year. Previous studies have shown that the parents' eating habits and consumption predicts their children's food intake (Oliveria et al. 1992; Woodward et al. 1996; Gibson et al. 1998; Hannon et al. 2003; Cooke et al. 2004; Vereecken et al. 2004; Lee et al. 2005; Wardle et al. 2005). Especially, parental fruit and vegetable intake has been shown to be predictors of the children's intake of these foods (Gibson et al. 1998; Cooke et al. 2004; Vereecken et al. 2004; Wardle et al. 2005). In an American study, poor diet quality of the mother was shown to be a valid indicator of poor diet quality of her infant or toddler (Lee et al. 2005). In addition to genetic factors, parents functioning as role models is one suggested explanation for this association (Fisher et al. 2002). Availability of foods is another possible explanation that is supported by this study. Frequent intakes of sweets/pastries was more common in children who had older siblings, suggesting that children eat what is available for their older siblings. It has also been suggested that the mothers' choice of foods during pregnancy can influence the child's future food preference (Mennella et al. 2001). 
Table 2(A). Frequency distribution (percentage of children) of intake of selected foods between the children who received sweets/pastries more often than one or two times per week and the children who received sweets/pastries one or two times per week or more seldom $(n \geq 10567)$

\begin{tabular}{|c|c|c|c|c|c|c|c|c|c|}
\hline \multirow[b]{2}{*}{ Food } & \multicolumn{2}{|c|}{ Daily } & \multicolumn{2}{|c|}{ 3-5 times/week } & \multicolumn{2}{|c|}{ 1-2 times/week } & \multicolumn{2}{|c|}{ More seldom } & \multirow[b]{2}{*}{$P$ value } \\
\hline & $\begin{array}{l}\text { Sweets } \\
>1-2 \text { times } \\
\text { /week }\end{array}$ & $\begin{array}{c}\text { Sweets } \\
\leq 1-2 \text { times } \\
\text { /week }\end{array}$ & $\begin{array}{l}\text { Sweets } \\
>1-2 \text { times } \\
\text { /week }\end{array}$ & $\begin{array}{l}\text { Sweets } \\
\leq 1-2 \text { times } \\
\text { /week }\end{array}$ & $\begin{array}{l}\text { Sweets } \\
>1-2 \text { times } \\
\text { /week }\end{array}$ & $\begin{array}{l}\text { Sweets } \\
\leq 1-2 \text { times } \\
\text { /week }\end{array}$ & $\begin{array}{l}\text { Sweets } \\
>1-2 \text { times } \\
\text { /week }\end{array}$ & $\begin{array}{l}\text { Sweets } \\
\leq 1-2 \text { times } \\
\text { /week }\end{array}$ & \\
\hline Fruit or berries & $66 \cdot 0$ & $72 \cdot 7$ & 24.0 & 19.2 & 7.9 & $5 \cdot 8$ & $2 \cdot 1$ & $2 \cdot 3$ & $<0.001$ \\
\hline Vegetables & 65.0 & $77 \cdot 0$ & $26 \cdot 6$ & $17 \cdot 8$ & $6 \cdot 8$ & 3.9 & 1.5 & $1 \cdot 3$ & $<0.001$ \\
\hline Potatoes & 33.5 & 43.2 & $59 \cdot 8$ & 52.5 & $6 \cdot 0$ & 3.8 & 0.7 & 0.5 & $<0.001$ \\
\hline Eggs & 0.4 & 0.1 & 3.3 & 1.5 & $24 \cdot 3$ & $15 \cdot 5$ & $72 \cdot 0$ & 82.9 & $<0.001$ \\
\hline Meat (beef) & $1 \cdot 1$ & 1.4 & $26 \cdot 6$ & $31 \cdot 3$ & 53.0 & $52 \cdot 0$ & $19 \cdot 2$ & $15 \cdot 2$ & $<0.001$ \\
\hline Pork, sausage & 3.5 & $2 \cdot 0$ & 50.9 & 41.0 & 40.4 & $46 \cdot 7$ & $5 \cdot 2$ & $10 \cdot 3$ & $<0.001$ \\
\hline Cheese & $18 \cdot 3$ & 13.7 & $27 \cdot 2$ & 23.1 & $22 \cdot 0$ & $21 \cdot 1$ & 32.4 & $42 \cdot 1$ & $<0.001$ \\
\hline Cream, crème fraiche & $2 \cdot 3$ & 1.5 & 13.9 & 8.7 & $35 \cdot 9$ & $26 \cdot 7$ & 47.9 & $63 \cdot 1$ & $<0.001$ \\
\hline Potato crisps & 0.3 & 0.1 & 0.4 & 0.1 & 14.0 & $2 \cdot 3$ & 85.2 & $97 \cdot 6$ & $<0.001$ \\
\hline Fried potatoes, French fries & 0.4 & 0.0 & 1.4 & 0.1 & $20 \cdot 1$ & $5 \cdot 8$ & $78 \cdot 1$ & 94.1 & $<0.001$ \\
\hline
\end{tabular}

Table 2(B). Frequency distribution (percentage of children) of intake of selected foods between the children who received sweets/pastries more often than one or two times per week and the children who received sweets/pastries one or two times per week or more seldom $(n \geq 10567)$

\begin{tabular}{|c|c|c|c|c|c|c|c|c|c|c|c|}
\hline \multirow[b]{2}{*}{ Food } & \multicolumn{2}{|c|}{0 times/d } & \multicolumn{2}{|c|}{$1-2$ times $/ \mathrm{d}$} & \multicolumn{2}{|c|}{$3-5$ times $/ \mathrm{d}$} & \multicolumn{2}{|c|}{$6-10$ times/d } & \multicolumn{2}{|c|}{ More often } & \multirow[b]{2}{*}{$P$ value } \\
\hline & $\begin{array}{l}\text { Sweets } \\
>1-2 \text { times } \\
\text { /week }\end{array}$ & $\begin{array}{l}\text { Sweets } \\
\leq 1-2 \text { times } \\
\text { /week }\end{array}$ & $\begin{array}{l}\text { Sweets } \\
>1-2 \text { times } \\
\text { /week }\end{array}$ & $\begin{array}{l}\text { Sweets } \\
\leq 1-2 \text { times } \\
\text { /week }\end{array}$ & $\begin{array}{l}\text { Sweets } \\
>1-2 \text { times } \\
\text { /week }\end{array}$ & $\begin{array}{l}\text { Sweets } \\
\leq 1-2 \text { times } \\
\text { /week }\end{array}$ & $\begin{array}{l}\text { Sweets } \\
>1-2 \text { times } \\
\text { /week }\end{array}$ & $\begin{array}{l}\text { Sweets } \\
\leq 1-2 \text { times } \\
\text { /week }\end{array}$ & $\begin{array}{c}\text { Sweets } \\
>1-2 \text { times } \\
\text { /week }\end{array}$ & $\begin{array}{c}\text { Sweets } \\
\leq 1-2 \text { times } \\
\text { /week }\end{array}$ & \\
\hline Bread & $2 \cdot 1$ & 4.9 & $87 \cdot 3$ & 88.6 & $10 \cdot 0$ & $6 \cdot 1$ & 0.5 & 0.3 & 0.1 & 0.1 & $<0.001$ \\
\hline Milk/sour milk/yoghurt & 2.9 & 3.9 & 67.5 & $72 \cdot 8$ & $28 \cdot 2$ & $22 \cdot 2$ & 1.2 & 1.0 & 0.2 & 0.0 & $<0.001$ \\
\hline
\end{tabular}


Table 3. Associations between parental demographic factors and children's intake of sweets/pastries at 1 year of age as well as time for introduction of sweets and sugar-sweetened drinks

\begin{tabular}{|c|c|c|c|c|c|c|c|c|c|}
\hline & \multicolumn{3}{|c|}{$\begin{array}{c}\text { Intake of sweets/pastries } \\
>1-2 \text { times/week }\end{array}$} & \multicolumn{3}{|c|}{$\begin{array}{l}\text { Introduction of sweets and } \\
\text { sugar at day } 240 \text { or earlier }\end{array}$} & \multicolumn{3}{|c|}{$\begin{array}{l}\text { Introduction of sugar-swee- } \\
\text { tened drinks at day } 240 \text { or } \\
\text { earlier }\end{array}$} \\
\hline & OR & $95 \% \mathrm{Cl}$ & $P$ & OR & $95 \% \mathrm{Cl}$ & $P$ & OR & $95 \% \mathrm{Cl}$ & $P$ \\
\hline High maternal intake of sweets during pregnancy & $2 \cdot 184$ & $1.957,2.437$ & 0.000 & $1 \cdot 216$ & $1.043,1.416$ & 0.012 & $1 \cdot 147$ & $0.998,1.319$ & 0.054 \\
\hline Child having older siblings & 1.507 & $1 \cdot 335,1.702$ & 0.000 & 0.919 & $0.781,1.083$ & 0.313 & 0.877 & $0.755,1.019$ & 0.086 \\
\hline Mother being $<25$ years old when giving birth & $1 \cdot 382$ & $1 \cdot 157,1 \cdot 651$ & 0.000 & $1 \cdot 207$ & $0.944,1.542$ & $0 \cdot 133$ & 1.691 & $1 \cdot 366,2 \cdot 093$ & 0.000 \\
\hline Father being $<25$ years old when child was born & 1.059 & $0.818,1.372$ & 0.663 & 1.089 & $0.769,1.542$ & 0.632 & $1 \cdot 142$ & $0.840,1.551$ & 0.397 \\
\hline Maternal smoking during pregnancy & $1 \cdot 209$ & $1.998,1.465$ & 0.052 & $1 \cdot 371$ & $1.045,1.798$ & 0.023 & 1.906 & $1 \cdot 508,2.410$ & 0.000 \\
\hline Mother living alone at time of birth of child & 1.901 & $1 \cdot 151,3 \cdot 139$ & 0.012 & $1 \cdot 307$ & $0.646,2.647$ & 0.456 & 2.671 & $1 \cdot 356,5 \cdot 261$ & 0.005 \\
\hline Maternal BMI $>25$ at 1-year examination & $1 \cdot 124$ & $0.996,1.269$ & 0.058 & $1 \cdot 306$ & $1 \cdot 107,1.540$ & 0.002 & $1 \cdot 341$ & $1.155,1.557$ & 0.000 \\
\hline Paternal BMI $>25$ at 1-year examination & 0.986 & $0 \cdot 882,1 \cdot 102$ & 0.803 & 0.943 & $0 \cdot 807,1 \cdot 101$ & 0.455 & 0.948 & $0.822,1.092$ & 0.457 \\
\hline Paternal education level & 0.904 & $0.819,0.998$ & 0.046 & 1.000 & $0.871,1.150$ & 0.993 & 0.926 & $0.813,1.054$ & 0.244 \\
\hline Maternal education level & 0.888 & $0.799,0.987$ & 0.028 & 0.957 & $0.824,1 \cdot 111$ & 0.562 & 0.692 & $0.603,0.794$ & 0.000 \\
\hline Father being from Sweden & $0 \cdot 819$ & $0.641,1.047$ & 0.111 & 0.907 & $0.640,1 \cdot 286$ & 0.090 & 0.744 & $0.537,1.031$ & 0.075 \\
\hline Mother being from Sweden & 0.783 & $0.605,1.013$ & 0.063 & 0.736 & $0.516,1.049$ & 0.583 & 0.551 & $0 \cdot 389,0.781$ & 0.001 \\
\hline Duration of exclusive breastfeeding & 0.983 & $0.954,1.013$ & $0 \cdot 260$ & 0.919 & $0.881,0.960$ & 0.000 & 3.339 & $0.885,0.954$ & 0.000 \\
\hline
\end{tabular}

OR, odds ratio adjusted for all other variables presented in the table.

It should be recognized that the mother's and children's dietary intake in the present study to a large degree is reported by the same person and could lead to overestimation of agreement between the two dietary patterns. However, the two food frequency questionnaires were carried out 1 year apart and should eliminate a memory effect in the reporting of dietary intake.

Parental education level has previously been reported to be associated with children's dietary pattern (Aranceta et al. 2003; Rogers \& Emmett, 2003; Cooke et al. 2004; Northstone \& Emmett, 2005). A high intake of snack foods (Aranceta et al. 2003) and junk food (Northstone \& Emmett, 2005) was more common in children of low-educated mothers while a higher vegetable intake (Cooke et al. 2004) was observed in children of parents with more education. In the population in the present study, both parents' education level was negatively associated with frequency of intake, while maternal education level was also negatively associated with early introduction of sugar-sweetened drinks. Other measures of socio-economic status like smoking during pregnancy and overweight $(\mathrm{BMI}>25)$ were associated with two of the feeding practices studied. Association to parental smoking was previously shown in a study from the UK where children of non-smokers consumed a diet that conformed more to guidelines on healthy eating (Rogers \& Emmett, 2003). Parental overweight has been shown to be an independent risk factor for overweight in children (Danielzik et al. 2004), but has to our knowledge not previously been related to early feeding of sugar-rich foods. Maternal age and marital status are also factors that according to the present study should be considered when identifying individuals at risk for a disadvantaged feeding pattern.

As many as $24 \%$ of 1-year-old children received chocolate, sweets or cakes/cookies more often than one or two times per week. This group of children had a less favourable dietary pattern which frequently included foods rich in fat. Several parental and demographic factors were associated with this feeding pattern, especially high intake of sweets/pastries during pregnancy. Screening of pregnant women for risk predictors like consumption of sweets, young age and smoking could be possible ways of identifying children at future risk for low dietary quality.

\section{Acknowledgements}

We are very thankful to all children and their parents participating in ABIS, as well as to the Health Centres where all questionnaires are collected and biological samples taken. This study, as a part of the ABIS project, was generously supported by JDRFWallenberg foundations (K 98-99D-12 813-01A), The Swedish Medical Research Council (MFR; Vetenskapsrådet; K99-72X11242-05A), The Swedish Child Diabetes Foundation (Barndiabetesfonden), The Swedish Diabetes Association, Swedish Diary Association R \& D, Novo Nordisk Foundation.

\section{References}

Aranceta J, Perez-Rodrigo C, Ribas L \& Serra-Majem L (2003) Sociodemographic and lifestyle determinants of food patterns in Spanish children and adolescents: the enKid study. Eur J Clin Nutr 57, Suppl. 1, S40-S44.

Bowman SA, Gortmaker SL, Ebbeling CB, Pereira MA \& Ludwig DS (2004) Effects of fast-food consumption on energy intake and diet quality among children in a national household survey. Pediatrics 113, $112-118$.

Cooke LJ, Wardle J, Gibson EL, Sapochnik M, Sheiham A \& Lawson M (2004) Demographic, familial and trait predictors of fruit and vegetable consumption by pre-school children. Public Health Nutr 7, 295-302.

Danielzik S, Czerwinski-Mast M, Langnase K, Dilba B \& Muller MJ (2004) Parental overweight, socioeconomic status and high birth weight are the major determinants of overweight and obesity in 5-7 y-old children: baseline data of the Kiel Obesity Prevention Study (KOPS). Int J Obes Relat Metab Disord 28, 1494-1502.

Fisher JO, Mitchell DC, Smiciklas-Wright H \& Birch LL (2002) Parental influences on young girls' fruit and vegetable, micronutrient, and fat intakes. J Am Diet Assoc 102, 58-64.

Foreyt JP \& Poston WS (2002) Consensus view on the role of dietary fat and obesity. Am J Med 113, Suppl. 9B, 60S-62S.

Gibson EL, Wardle J \& Watts CJ (1998) Fruit and vegetable consumption, nutritional knowledge and beliefs in mothers and children. Appetite 31, 205-228.

Hannon PA, Bowen DJ, Moinpour CM \& McLerran DF (2003) Correlations in perceived food use between the family food preparer and their spouses and children. Appetite 40, 77-83. 
Kranz S \& Siega-Riz AM (2002) Sociodemographic determinants of added sugar intake in preschoolers 2 to 5 years old. $J$ Pediatr 140, $667-672$

Lee SY, Hoerr SL \& Schiffman RF (2005) Screening for infants' and toddlers' dietary quality through maternal diet. MCN Am J Matern Child Nurs 30, 60-66.

Ludwig DS, Peterson KE \& Gortmaker SL (2001) Relation between consumption of sugar-sweetened drinks and childhood obesity: a prospective, observational analysis. Lancet 357, 505-508.

Mennella JA, Jagnow CP \& Beauchamp GK (2001) Prenatal and postnatal flavor learning by human infants. Pediatrics 107, E88.

National Food Administration (Livsmedelsverket) (2003) Hur mycket socker äter vi? (How much sugar do we eat?). http://www.slv.se/ templates/SLV_Page.aspx $?$ id $=7604$ (accessed 29 November 2005).

Nordic Council of Ministers (2004) Nordic Nutrition Recommendations 2004, 4th ed, Copenhagen: Nord.

North K \& Emmett P (2000) Multivariate analysis of diet among threeyear-old children and associations with socio-demographic characteristics. The Avon Longitudinal Study of Pregnancy and Childhood (ALSPAC) Study Team. Eur J Clin Nutr 54, 73-80.

Northstone K \& Emmett P (2005) Multivariate analysis of diet in children at four and seven years of age and associations with socio-demographic characteristics. Eur J Clin Nutr 59, 751-760.

Oliveria SA, Ellison RC, Moore LL, Gillman MW, Garrahie EJ \& Singer MR (1992) Parent-child relationships in nutrient intake: the Framingham Children's Study. Am J Clin Nutr 56, 593-598.
Overby NC, Lillegaard IT, Johansson L \& Andersen LF (2004) High intake of added sugar among Norwegian children and adolescents. Public Health Nutr 7, 285-293.

Parsons TJ, Power C, Logan S \& Summerbell CD (1999) Childhood predictors of adult obesity: a systematic review. Int J Obes Relat Metab Disord 23, Suppl. 8, S1-S107.

Pepino MY \& Mennella JA (2005) Factors contributing to individual differences in sucrose preference. Chem Senses 30, Suppl. 1, i319-i320.

Rogers I \& Emmett P (2003) The effect of maternal smoking status, educational level and age on food and nutrient intakes in preschool children: results from the Avon Longitudinal Study of Parents and Children. Eur J Clin Nutr 57, 854-864.

Shahar D, Shai I, Vardi H, Shahar A \& Fraser D (2005) Diet and eating habits in high and low socioeconomic groups. Nutrition 21, 559-566.

Wardle J, Carnell S \& Cooke L (2005) Parental control over feeding and children's fruit and vegetable intake: how are they related? J Am Diet Assoc 105, 227-232.

Vereecken CA, Keukelier E \& Maes L (2004) Influence of mother's educational level on food parenting practices and food habits of young children. Appetite 43, 93-103.

Woodward DR, Boon JA, Cumming FJ, Ball PJ, Williams HM \& Hornsby H (1996) Adolescents' reported usage of selected foods in relation to their perceptions and social norms for those foods. Appetite 27, 109-117. 